\title{
The thermal diffusivity and conductivity of transformation-toughened solid solutions of alumina and chromia
}

\author{
D. P. H. HASSE LMAN, R. SYED \\ Department of Materials Engineering, Virginia Polytechnic Institute and State \\ University, Blacksburg, Virginia 24061, USA \\ T.-Y. TIEN \\ Department of Materials and Metallurgical Engineering, The University of Michigan, \\ Ann Arbor, Michigan 48109, USA
}

The thermal diffusivity of a series of solid solutions of alumina and chromia transformation toughened with a dispersed phase of unstabilized zirconia was measured by means of the laser-flash method from room temperature to $1400^{\circ} \mathrm{C}$. It was found, in general, that the thermal diffusivity could be decreased significantly by the combined effects of solid solution alloying, microcracking and by the presence of the low conductivity dispersed phase of zirconia. The decrease in thermal diffusivity by microcracking was found to be present in the solid solution with low chromia content which underwent extensive grain growth. The effectiveness of solid solution formation and microcracking on thermal diffusivity was found to be greatest at the lower and intermediate ranges of temperature. The decrease in the thermal diffusivity due to the zirconia inclusions was found to be effective over the total temperature range. A numerical example is presented for the thermal conductivity calculated from the thermal diffusivity multiplied by the volumetric heat capacity.

\section{Introduction}

The increasing trends in many fields of engineering such as energy conversion, chemical processing and aerospace, towards ever increasing operating temperatures places complex demands on the development and selection of materials to meet design requirements and long-term satisfactory performance. In general, candidate materials for functions which involve high temperature should exhibit melting points well in excess of the use temperature, as well as high chemical and structural stability. For specific design situations the magnitude of the thermo-physical properties can also play a vital role in assuring prescribed performance criteria. For instance, materials for heat exchangers should exhibit values for thermal conductivity as high as possible. In contrast, for many other designs, the choice of the optimum material is based on its thermal insulating ability which requires values for thermal conductivity which are as low as possible.

Structures and components which operate at high temperatures inevitably are subjected to high steady state or transient heat fluxes. The resulting spatially non-uniform temperature distributions can lead to thermal stresses of high magnitude. Because of their nature of atomic bonding and more complex crystal structures candidate materials for high temperature service tend to be highly brittle. Because of such brittleness, failure under the influence of thermal stresses can be highly catastrophic, rendering the structure of component totally unsuitable for continued satisfactory service [1]. For this reason, in the design and selection of materials considerable emphasis must be placed on avoiding failure by thermal stresses. It has been established in general, that materials with high resistance to thermal stress failure should 
exhibit high values for the tensile fracture stress and thermal conductivity in combination with low values for the coefficient of thermal expansion and Young's modulus of elasticity [2, 3]. High fracture toughness also is desirable as it will assure a high tensile failure stress for a material with given crack size; more important is that a high fracture toughness also assures rapid crack arrest following the initiation of thermal crack propagation [1]. This latter criterion is critical for those design situations for which the thermal stresses are of such magnitude that even in the optimum material the initiation of thermal stress failure cannot be avoided.

It is critical to note that materials with high thermal conductivity chosen specifically to avoid thermal stress failure also will conduct a great deal of heat while in service. Such conduction of heat represents no problem for these designs, such as heat exchangers, for which the material of construction should exhibit high thermal conductivity in order to meet design requirements.

However, the requirement of high thermal conductivity for resistance to thermal stress failure is incompatible with the requirement of low conductivity for those materials which serve as thermal insulators in those designs for which heat losses must be kept to a minimum. Clearly, for the latter situation design trade-offs need to be made. Alternatively new materials need to be developed which exhibit improved thermal insulating ability in combination with enhanced resistance to thermal stress failure. One way this can be achieved is by the inducement of extensive microcrack formation, which lowers thermal conductivity significantly [4] and simultaneously transforms the highly unstable mode of thermal crack propagation to the more desirable stable mode which leads to rapid crack arrest [1]. Unfortunately spontaneous microcracking leads to a significant decrease in the tensile fracture stress and possible fracture toughness as well. Clearly, for the development of materials with low thermal conductivity and high fracture toughness an alternative approach must be sought.

One such alternative is to take advantage of a number of independent effects. Significant decreases in thermal conductivity can be achieved by two effects, namely solid solution alloying $[5$, 6] and the inclusion of second-phase dispersions with a thermal conductivity lower than the matrix material $[7,8]$. Fracture toughness can be increased significantly by the effect of transformation toughening, specifically by the addition of a dispersed phase of unstabilized zirconia $[9,10]$. Such transformation toughening has been shown experimentally to significantly increase thermal stress resistance as well [11]. Zirconium oxide has a value of thermal conductivity substantially lower than the corresponding value for most structural materials for high temperature applications. For this reason the presence of a dispersed phase of unstabilized zirconia simultaneously leads to an increase in fracture toughness and thermal stress resistance coupled with a decrease in thermal conductivity. Microcrack formation in the matrix which can be associated with the zirconia dispersed phase can enhance thermal stress resistance and lower the thermal conductivity further. Finally, even lower values of the thermal conductivity can be obtained by choosing a matrix phase which is a solid solution rather than a high-purity single phase material.

A newly developed material in which the above effects have been combined to achieve the desirable combination of increased fracture toughness and decreased thermal conductivity consists of zirconia-transformation-toughened solid solution of alumina and chromia. The characterization of the thermal diffusivity/conductivity of this system is the subject of this study. Mechanical properties and other data have been reported earlier [12].

\section{Experimental procedure}

\subsection{Sample preparation}

The specimens were prepared from powders obtained from solutions containing the metal ions of one half normality, prepared by dissolving the soluble salts: $\mathrm{Al}\left(\mathrm{NO}_{3}\right)_{3} .9 \mathrm{H}_{2} \mathrm{O} ; \mathrm{Cr}\left(\mathrm{NO}_{3}\right)_{3} .9 \mathrm{H}_{2} \mathrm{O}$; $\mathrm{ZrOCl}_{2} .3 \mathrm{H}_{2} \mathrm{O}$; and $\mathrm{HfOCl}_{2} .8 \mathrm{H}_{2} \mathrm{O}$ in water. Appropriate amounts of solution were mixed and were added slowly to an $\mathrm{NH}_{4} \mathrm{OH}$ solution while stirring. A pH value of 8 of the mixed solutions was maintained during precipitation. The mixtures were kept at $70^{\circ} \mathrm{C}$ for $30 \mathrm{~min}$ while stirring. The precipitates were then filtered, washed with dilute ammonia solution, and dried at $110^{\circ} \mathrm{C}$ for $24 \mathrm{~h}$. The dried precipitates were calcined at $500^{\circ} \mathrm{C}$ for $2 \mathrm{~h}$ and ground for $10 \mathrm{~h}$ in a ball mill. The calcined powders were amorphous to X-ray. The co-precipitated powders were then hot pressed to full density at $1500^{\circ} \mathrm{C}$ for $30 \mathrm{~min}$ in $\mathrm{BN}$-coated graphite dies under a pressure of $30 \mathrm{MPa}$. 

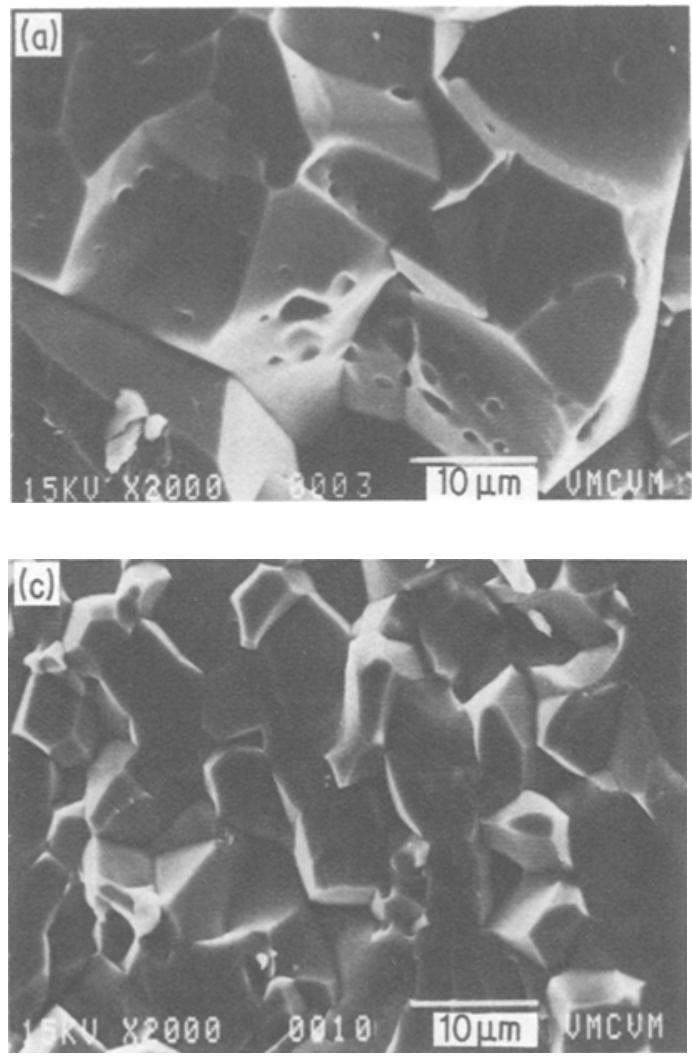

\subsection{Microstructures}

Fig. 1 shows scanning electron fractographs of samples of alumina with 0,20 and $50 \mathrm{~mol} \%$ chromia without zirconia. It is clearly evident that the grain size decreases with increasing content of chromia which appears to act as a grain-growth inhibitor.

Fig. 2 shows scanning electron fractographs of alumina with 0,20 and $50 \mathrm{~mol} \%$ chromia plus 15 vol $\%$ zirconia. Comparison with Fig. 1 shows that for a given chromia content the presence of the zirconia inclusions serves to decrease the grain size even further.

\subsection{Measurement of thermal diffusivity}

The flash method [13] was used for the measurement of the thermal diffusivity, using a glass $-\mathrm{Nd}$ laser as the source. The method basically consists of subjecting one face of a specimen in the form of a thin plate to a single laser flash and monitoring the transient temperature response of the opposite face. The specimens for this study, approximately $8 \mathrm{~mm}$ square by $2 \mathrm{~mm}$ thick, were cut from the larger blocks with the aid of a slowspeed high-precision diamond saw. The surface of the specimens was coated with carbon to

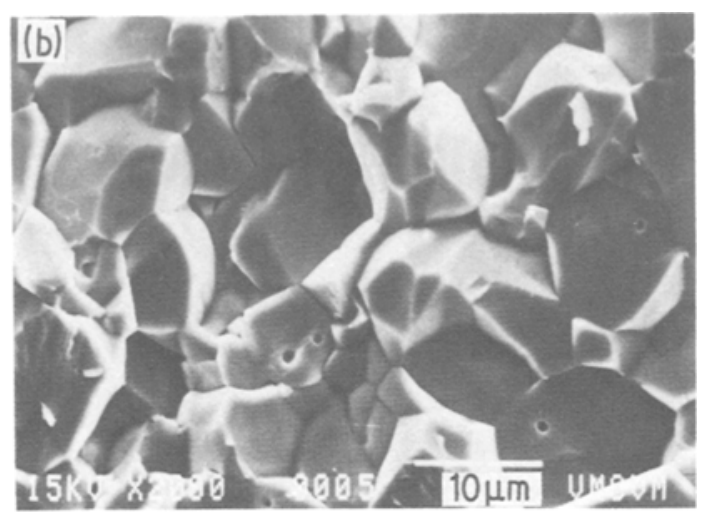

Figure I Scanning electron fractographs of solid solutions of alumina and chromia with (a) 0 ; (b) 20 and (c) $50 \mathrm{~mol} \%$ chromia.

assure complete absorption of the energy of the laser flash. For measurements at elevated temperatures the specimens were placed in a suitable holder located in the centre of a carbon resistance furnace with nitrogen atmosphere. The transient temperature of the opposite face of the specimen was monitored with a liquid $\mathrm{N}_{2}$ cooled InSb infra-red detector from ambient temperatures ranging from 25 to about $600^{\circ} \mathrm{C}$ and with a silicon photodiode above these temperatures. The total length of time of the measurement of the thermal diffusivity as a function of temperature, including data acquisition during cooling, took approximately six hours.

\section{Results and discussion}

Fig. 3 shows the data for the thermal diffusivity at room temperature for the alumina-chromia solid solutions with and without the zirconia dispersed phase as a function of chromia content. For the samples without zirconia the thermal diffusivity exhibits a monotonic decrease with increasing chromia content, with a relative difference of a factor $\sim 4$ over the total range of chromia content. In general, such a significant decrease in thermal diffusivity is in qualitative agreement with corresponding data for the thermal conductivity and diffusivity for alumina-chromia solid solutions reported by others $[5,6]$.

The solid solution series with zirconia dispersions shows a completely different behaviour with the peak value of the thermal diffusivity occurring at an intermediate value of chromia contact. The data for the samples with $20 \mathrm{~mol} \%$ chromia or higher fall below, but are parallel to, the data for 

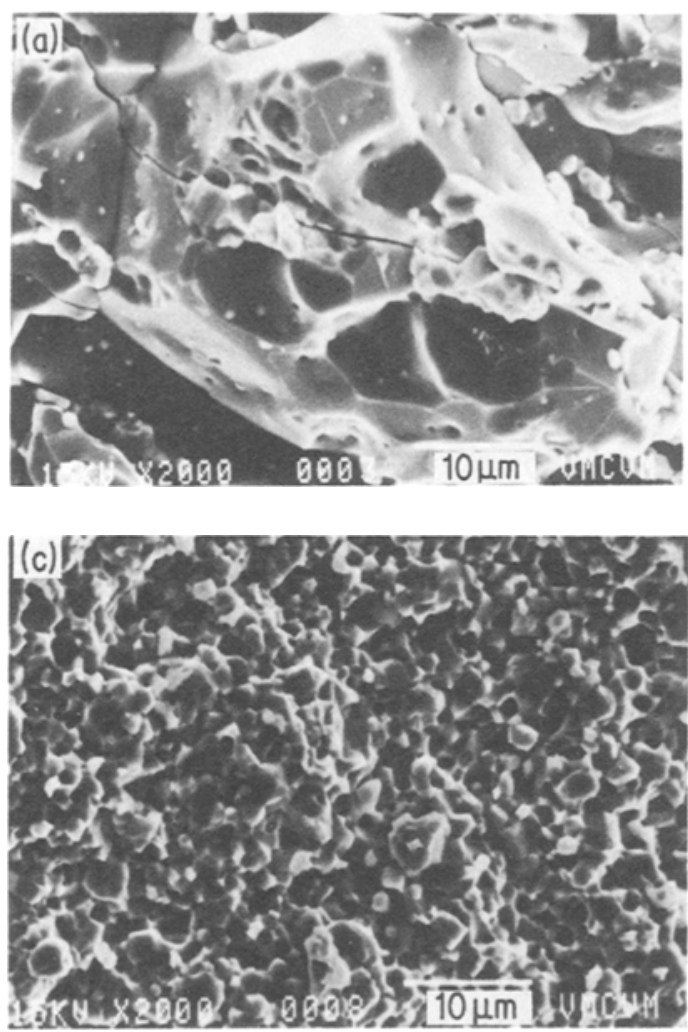

the samples without zirconia. These differences are thought to be due primarily to the effect of the zirconia particles on the thermal diffusivity. Because zirconia has a thermal diffusivity and conductivity [14-16] well below the values for the solid solution matrix, the zirconia inclusions should result in a decrease in the thermal diffusivity as expected from composite theory [7, 8].

The solid solution samples with zirconia inclusions with less than $20 \%$ chromia appear to exhibit an anomalous behaviour compared to the solid solution samples without zirconia inclusions. This apparent anomaly is thought to be related to the extensive grain growth during sintering of the samples with low chromia content. Specifically, it is suggested that this effect is due to the formation of microcracks which occurs more readily in coarse-grained rather than fine-grained materials $[17,20]$. Because microcracks form preferentially at grain boundaries, they are not readily evident in the SEM-fractographs shown in Figs. 1 and 2. However, that the anomolous behaviour is due to microcrack formation can be established by indirect evidence. If no other effects were present it is reasonable to anticipate that the data for the

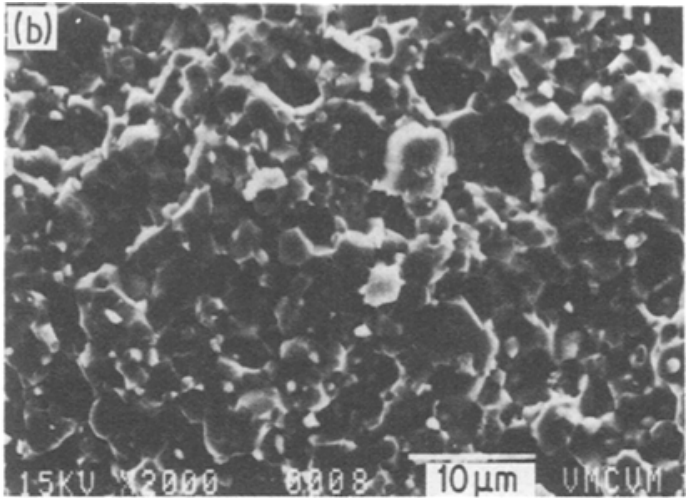

Figure 2 Scanning electron fractographs of solid solutions of alumina and chromia with (a) 0 ; (b) 20 and (c) $50 \mathrm{~mol} \%$ chromia and 15 vol \% zirconia.

thermal diffusivity of the specimens with 0 and $10 \mathrm{~mol} \%$ chromia with zirconia would lie on a curve obtained by extrapolation of the data for the specimens with more than $20 \mathrm{~mol} \%$ chromia which lies parallel to the curve for the solid solution specimens without zirconia. The actual experimental values for the samples with 0 and $10 \mathrm{~mol} \%$ chromia fall below this extrapolated curve by a factor of about three. This latter value agrees with the observed factor of three decrease in the thermal diffusivity of coarse-grained fully microcracked polycrystalline aggregates $[21,22]$. The

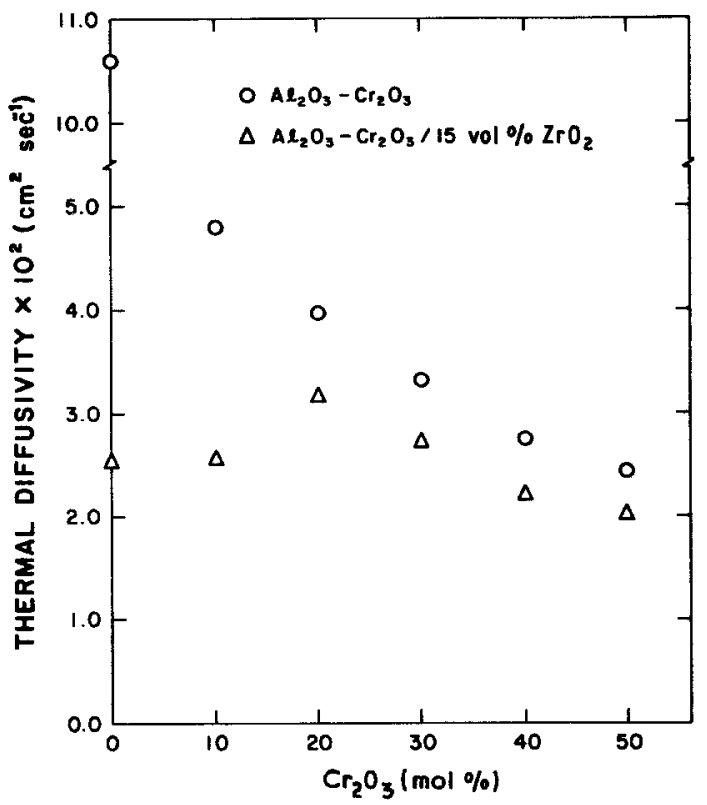

Figure 3 Thermal diffusivity at room temperature of solid solutions of alumina and chromia with or without a dispersed phase of $15 \mathrm{vol} \%$ zirconia as a function of chromia content. 
experimental data for the temperature dependence of the thermal diffusivity for the specimens with low chromia content to be presented later also indirectly confirm the presence of microcracks.

For the present samples, microcrack formation can be attributed to two possible effects, namely the mismatch in the coefficients of thermal expansion of the zirconia and the alumina-chromia solid solution or due to the increase in volume of the zirconia particles as the result of the tetragonal to monoclinic phase transformation. X-ray analysis of the samples with the anomalously low thermal diffusivity showed the relative amounts of the tetragonal and monoclinic phases not to be significantly different from the samples with $50 \mathrm{~mol} \%$ chromia which presumably are free of microcracks. This indicates that the thermal expansion mismatch between the zirconia and the alumina-chromia matrix appears to be the primary mechanism of microcrack formation.

Figs. 4a to $\mathrm{d}$ show the experimental data for the temperature dependence of the thermal diffusivity of the solid solution with $0,10,20$ and 50 mol\% with and without the zirconia dispersed phase. For the specimens with 20 and $50 \mathrm{~mol} \%$ chromia, at least qualitatively, the temperature dependence is typical for dielectric materials with phonon transport as the primary mechanism for heat transfer. For the samples with $50 \mathrm{~mol} \%$ chromia, however, the relative temperature dependence of the thermal diffusivity is less than the corresponding dependence for the samples with 20 mol\% chromia. This effect arises because at the higher chromia contents the thermal diffusivity is affected by the temperature independent phononsolute atom interactions which suppress the strongly temperature dependent effect of phononphonon collisions on thermal diffusivity. In this respect, it is of interest to note that at the highest level of temperature the thermal diffusivity for the samples with 20 and $50 \mathrm{~mol} \%$ chromia are comparable. This suggests that solid solution alloying is most effective in lowering the thermal diffusivity at low to intermediate temperatures, rather than at the highest ranges of temperature of this study. In contrast, for the samples with chromia contents of $20 \mathrm{~mol} \%$ or higher, the zirconia is effective in lowering the thermal diffusivity by about $20 \%$ over the total temperature range.

The samples with 0 or $10 \mathrm{~mol} \%$ chromia without zirconia, as shown in Figs. $4 a$ and $b$, exhibit a temperature dependence typical for a dielectric with phonon transport as the primary mechanism for heat conduction. The data for the alumina without chromia and zirconia compare very favourably with the values which can be inferred from the data for the thermal conductivity of pure high-density alumina [5].

The samples with 0 and $10 \mathrm{~mol} \% \mathrm{Cr}_{2} \mathrm{O}_{3}$ with the zirconia as shown by the data given in Figs. $4 \mathrm{a}$ and $b$, exhibit a temperature dependence which is distinctly different from the corresponding behaviour for the other samples. The data obtained during cooling from the higher temperatures do not retrace the data obtained during the initial heating phase of the heating and cooling cycle. Both these effects are typical for polycrystalline aggregates $[21,22]$ and composites [23] which undergo extensive microcracking. The suppressed temperature arises from two mutually compensating effects. The thermal diffusivity will decrease with increasing temperature due to the normal phonon processes. This effect, however, is offset by crack closure and possibly crack healing on heating the specimen towards the temperature at which it was fabricated, which would lead to an increase in thermal diffusivity.

At the highest levels of temperature crack healing can take place by diffusional or other processes which should lead to an increase in the thermal diffusivity. For this reason, during a heating and cooling cycle the data on cooling, at least at those temperatures at which no new microcrack formation will occur, should exceed the values obtained during the heating phase of the cycle, as observed.

It should also be noted that Figs. $4 \mathrm{a}$ and $\mathrm{b}$ indicate that the data obtained on cooling cross over the data on heating, so that on return to room temperature the thermal diffusivity exhibits a permanent decrease. This effect is thought to be the result of the formation of microcracks in addition to those formed during the initial cooling from the manufacturing temperature. Such an effect is expected if microcrack formation at the higher temperatures involves a stage of sub-critical growth from microcrack precursors such as pores. If so, the microcrack density would be expected to be a function of time or number of cooling cycles. Regardless of the details the data in Figs. $4 a$ and $b$ clearly indicate that the thermal diffusivity and possibly other properties of microcracked materials can be a function of thermal history.

The closure and healing of microcracks at the 


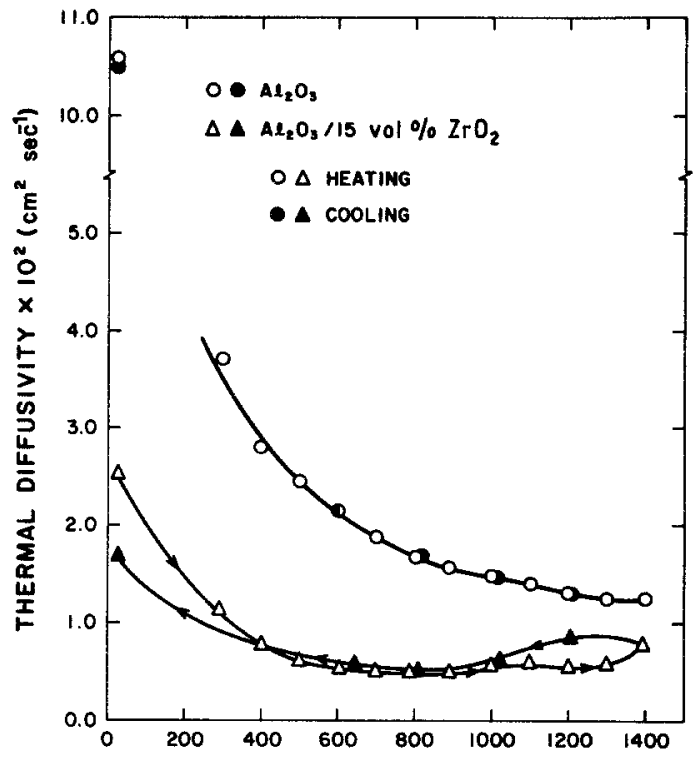

(a)

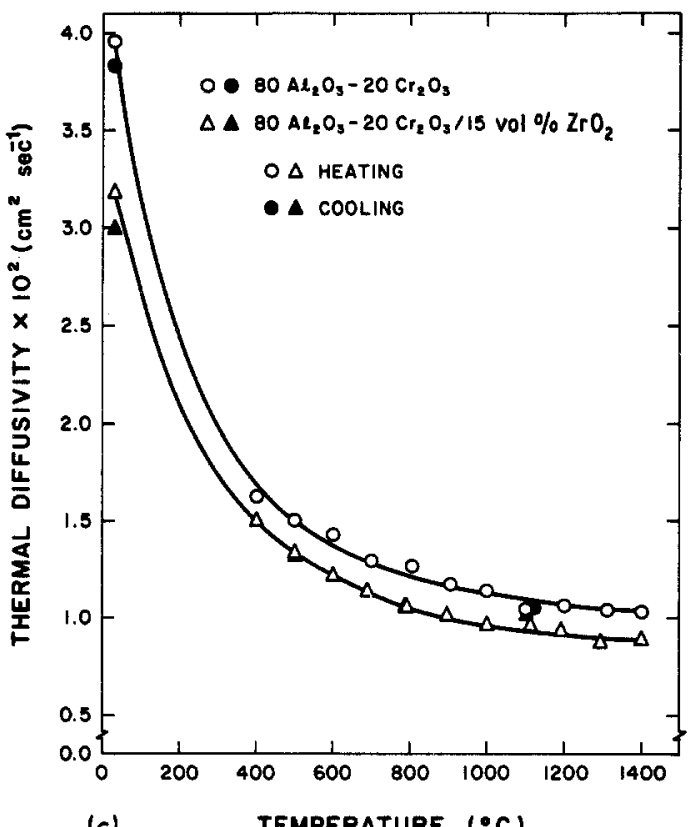

(c)
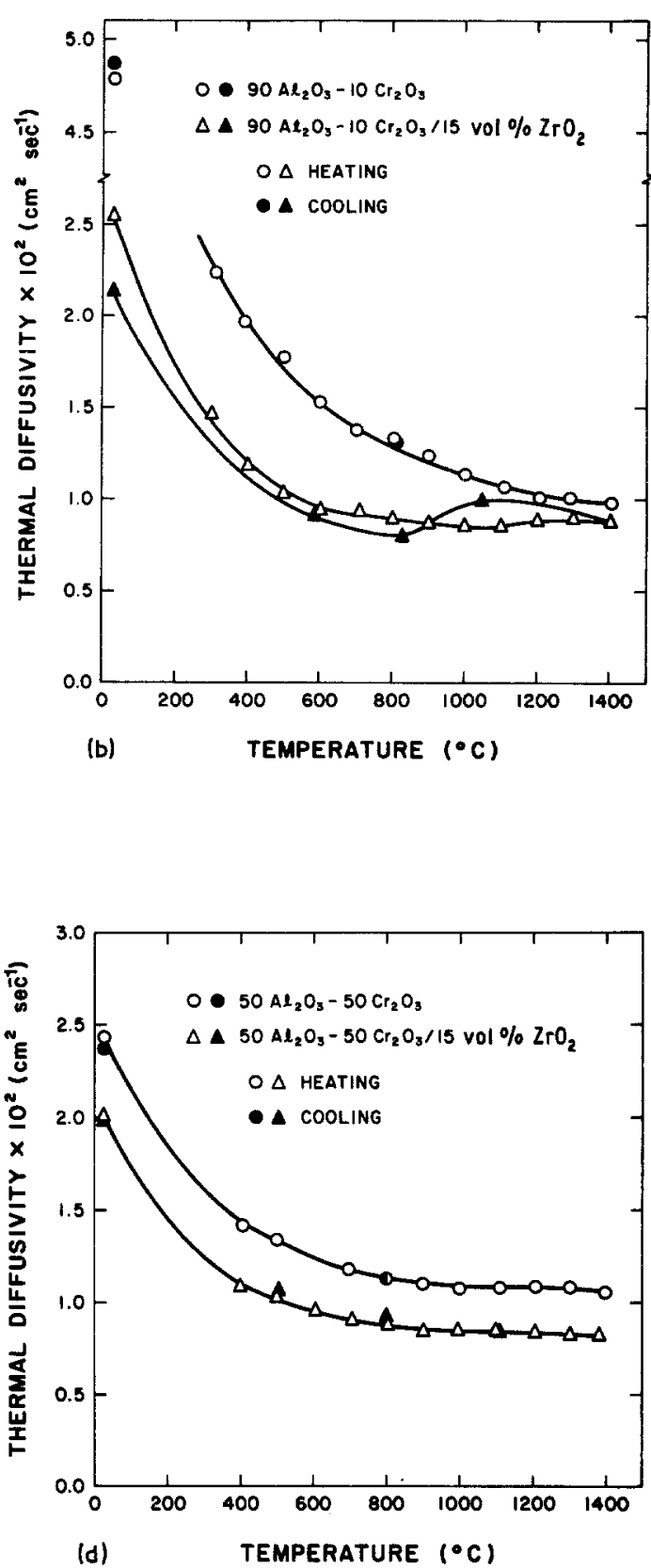

Figure 4 Temperature dependence of the thermal diffusivity of alumina-chromia solid solutions with or without 15 vol \% zirconia inclusions.

higher temperatures will cause the thermal diffusivity to approach the value corresponding to the crack-free material. For this reason, the mechanism of microcracking for the reduction of the thermal diffusivity and conductivity is expected to be most effective at the lower ranges of temperature over which the cracks exhibit their maximum size and crack-opening displacement.

For estimates of heat losses, necessary for pur- poses of optimizing a specific design, data are required for the thermal conductivity especially for conditions of steady state heat flow. These can be obtained by multiplication of the experimental data for the thermal diffusivity with the volumetric heat capacity, the product of the specific heat and density. For purposes of saving space, as a numerical example, the thermal conductivity was calculated for the solid solution with $80 \mathrm{~mol} \%$ 


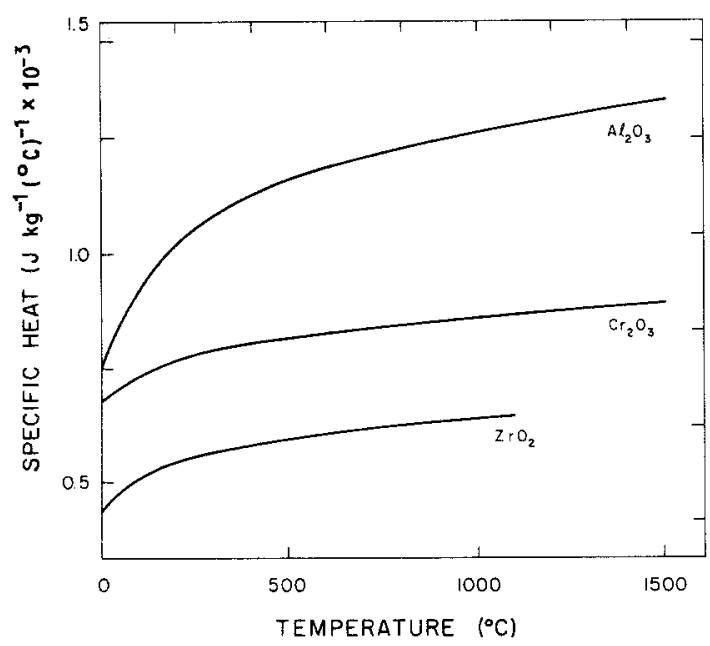

Figure 5 Specific heat of alumina, chromia and zirconia (after Touloukian et al. [24]).

$\mathrm{Al}_{2} \mathrm{O}_{3}$ and $20 \mathrm{~mol} \% \mathrm{Cr}_{2} \mathrm{O}_{3}$ using the experimental data in Fig. 4c. The values of the volumetric heat capacity were obtained from the measured value of density and literature data [24] for the specific heat of the individual oxides shown in Fig. 5 which were assumed to be appropriate for the materials of this study. The resulting values of the thermal conductivity are presented in Fig. 6. These values show a similar relative temperature dependence as the data for the thermal diffusivity given in Fig. 4c. Because of the increase in specific heat with increasing temperature, quantitatively the relative temperature dependence of the thermal

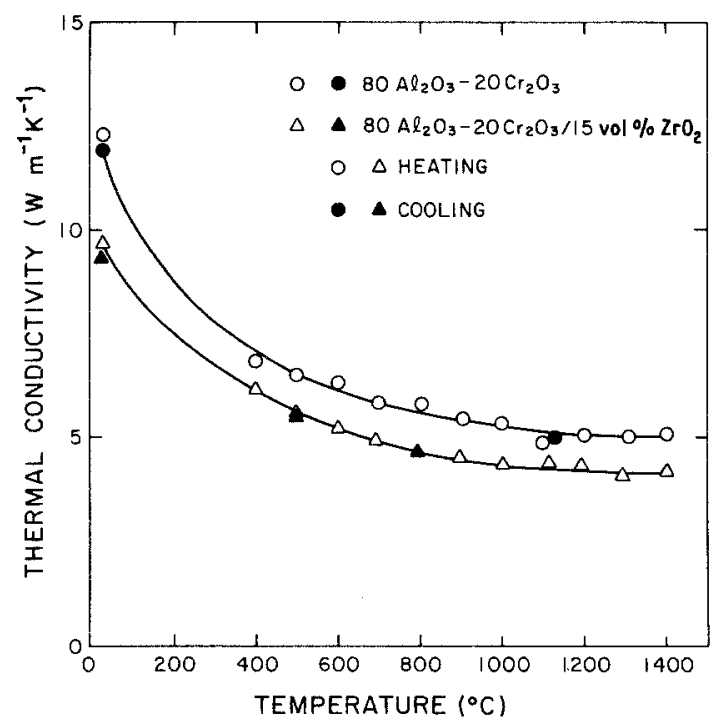

Figure 6 Thermal conductivity of alumina-chromia solid solutions with $20 \mathrm{~mol} \%$ chromia without and with a 15 vol\% dispersed phase of zirconia. conductivity at any temperature differs from the corresponding temperature dependence of the thermal diffusivity. For all compositions, the earlier conclusions about the relative effects of solid solution alloying, microcracking and the presence of the zirconia dispersed phase on thermal diffusivity also will apply to the effects of these same variables on thermal conductivity.

In this respect, two general recommendations can be made in regard to the desired composition and associated microstructure which for the present composite system will yield minimum values of the thermal conductivity, i.e. optimum thermal insulating behaviour. As shown in Fig. 5, the value for the specific heat (per unit mass) of the chromia is significantly less than the corresponding value for the alumina especially at the higher values of temperature. Even taking into account the differences in density, the volumetric heat capacity of the chromia is still significantly less than the corresponding value for the alumina. For this reason, the lowest value for the thermal conductivity for the present series of compositions will be obtained at the highest level of chromia content.

A speculation can be made on how to reduce the thermal conductivity of the compositions of this study even further. As indicated by the data shown in Fig. 3 , the relative decrease in the thermal diffusivity at room temperature which can be achieved at the higher levels of chromia content is of the order of the relative decrease attainable by microcracking at zero or low values of chromia content. This implies that if microcracking could be induced in the compositions with the higher value of chromia content, values for the thermal diffusivity and corresponding values for the thermal conductivity would have been achieved significantly lower than those observed. At least in principle, this could be achieved by modifications of the processing conditions such that grain growth is promoted for those compositions with the higher values of chromia content.

In summary, the results of this study have demonstrated that the thermal diffusivity and conductivity of dielectric materials can be reduced significantly by the combined effects of solid solution alloying, microcrack formation and by inclusion of a low thermal conductivity dispersed phase. Unstabilized zirconia as such a dispersed phase has the additional advantage that by the mechanism of phase-transformation toughening, the decrease in 
thermal diffusivity and conductivity is accompanied by an enhanced fracture toughness as well as thermal stress resistance.

\section{Acknowledgements}

The measurement of the thermal diffusivity was conducted as part of a programme funded by the Office of Naval Research under Contract N00 01478-C-0431. The specimens were prepared with the support provided by the Army Materials and Mechanics Research Center under contract DAAG 46-84-K-0001.

\section{References}

1. D. P. H. HASSElman, J. Amer. Ceram. Soc. 52 (1969) 600.

2. W. D. KINGERY, ibid. 38 (1955) 3.

3. D. P. H. hasSElmaN, Bull. Amer. Ceram. Soc. 49 (1970) 1933.

4. Idem, J. Compos. Mater. 12 (1978) 403.

5. W. D. KINGERY, H. K. BOWER and D. R. UHL. MANN, "Introduction to Ceramics" (John Wiley, New York, 1976).

6. J. E. MATTA and D.-P. H. HASSELMAN, J. Amer. Ceram. Soc, 58 (1975) 458.

7. Z. HASHIN, J. Compos. Mater. 2 (1968) 284.

8. S. C. CHENG and R. I. VACHON, Int. J. Heat. Mass Transfer 12 (1969) 249.

9. N. Claussen, J. Amer. Ceram. Soc. 59 (1976) 49.

10. A. G. EVANS and A. H. HEUER, ibid. 63 (1980) 241.

11. N. CLAUSSEN and D. P. H. HASSELMAN, in "Thermal Stresses in Severe Environments", edited by D.P. H. Hasselman and R. A. Heller (Plenum Press, New York, 1980) pp. 381-395.
12. T. K. BROG, J. W. JONES and T. Y. TIEN, "Proceedings of 21 st Automotive Technology Development Contractors Coordination Meeting", November 15, 1983 (Society of Automotive Engineers, Detroit, Michigan, 1984) pp. 207-14.

13. W. J. PARKER, R. J. JENKINS, C. P. BUTLER and G. L. ABBOTT, J. Appl. Phys. 32 (1961) 1679.

14. W. D. KINGERY, J. PAPIS, M. E. DOTY and D. C. HILL, J. Amer. Ceram. Soc. 42 (1959) 393.

15. V. C. MIRKOVITCH, ibid. 48 (1965) 387.

16. R. C. GARVIE, J. Mater. Sci. 11 (1976) 1365

17. R. W. RICE and R. C. POHANKA, J. Amer. Ceram. Soc. 62 (1979) 559.

18. E. D. CASE and J. R. SMYTH, Mater. Sci. Eng. 51 (1981) 175 .

19. Y. FU and A. G. EVANS, Acta Metall. 30 (1982) 1619.

20. A. G. EVANS and D. R. CLARKE, in "Thermal Stresses in Severe Environments", edited by D. P. H. Hasselman and R. A. Heller (Plenum Press, New York, 1980) pp. 629-48.

21. H. J. SIEBENECK, D. P. H. HASSELMAN, J. J. CLEVELAND and R. C. BRADT, J. Amer. Ceram. Soc. 59 (1976) 241.

22. Idem, ibid. 60 (1977) 336 .

23. L. D. BENTSEN and D. P. H. HASSELMAN, in "Thermal Conductivity 18", edited by T. Ashworth (Plenum Press) in press.

24. Y. S. TOULOUKIAN, R. W. POWELL, C. Y. HO and M. C. NICOLAOU, in "Thermophysical Properties of Matter", Thermo-Physical Research Center Series, Vol. 5 - Specific Heat-Non-metallic Solids" (Plenum Press, New York, 1973).

Received 15 August

and accepted 13 September 1984 